\title{
Hybrid Cardiac Surgery in a Patient with Cardiogenic Shock and Ongoing Myocardial Ischemia
}

\author{
${ }^{1}$ Hiremathada Shanmukh, ${ }^{2}$ Ravi S Shetty
}

\begin{abstract}
Suitable time for coronary artery bypass grafting (CABG) after acute myocardial infarction (AMI) remains controversial. Many randomized studies have shown that primary angioplasty in AMI may result in better results compared with fibrinolytic therapy and CABG. We herewith report a case of a 72-yearold patient with fracture of femur who sustained massive myocardial infarction (MI). Hybrid cardiac surgery which combines percutaneous coronary intervention and CABG was performed on him.
\end{abstract}

Keywords: Angioplasty, Coronary artery bypass grafting, Hybrid coronary revascularization, Percutaneous coronary intervention.

How to cite this article: Shanmukh H, Shetty RS. Hybrid Cardiac Surgery in a Patient with Cardiogenic Shock and Ongoing Myocardial Ischemia. J Med Sci 2018;4(2):57-59.

Source of support: Nil

Conflict of interest: None

\section{INTRODUCTION}

Nowadays, cardiac surgeons are confronted with an increasingly higher number of high-risk patients. Coronary artery bypass grafting in this population is still associated with high morbidity and mortality rates in spite of improvements in various techniques including surgical and cardiopulmonary bypass (CPB) procedures. ${ }^{1-3}$ Hybrid coronary revascularization is a technique that involves a percutaneous intervention followed by beating-heart CABG. This has recently been introduced into cardiac surgery. ${ }^{2,4,5}$ This alternative strategy takes advantage of both surgical and interventional techniques. This technique may benefit poor patients at risk, as it avoids or uses minimal CPB which will reduce postoperative complications.

\footnotetext{
${ }^{1,2}$ Chief Surgeon

${ }^{1}$ Department of Cardiothoracic and Vascular Surgery, SDM College of Medical Sciences \& Hospital, Dharwad, Karnataka India

${ }^{2}$ Department of Cardiothoracic and Vascular Surgery, M.S. Ramaiah Medical College, Bengaluru, Karnataka, India

Corresponding Author: Hiremathada Shanmukh, Chief Surgeon, Department of Cardiothoracic and Vascular Surgery SDM College of Medical Sciences \& Hospital, Dharwad Karnataka, India, e-mail: cshanmuk@yahoo.com
}

\section{CASE REPORT}

A 72-year-old male was admitted with fracture of left femur neck. During the course in the hospital, he sustained massive anterior wall MI. He subsequently developed acute left ventricular failure (LVF) and pulmonary edema. Eventually, he was electively intubated and put on ventilator. Intra-aortic balloon pump (IABP) was inserted along with inotropic support. He continued to have ST elevations in lateral leads and ongoing ischemia. His cardiac index was $1.4 \mathrm{~L} / \mathrm{min} / \mathrm{m}^{2}$.

Angiogram was performed which showed severe triple vessel disease, with critical lesion in mid-circumflex artery (Fig. 1). Vessels were also found to be calcified. Angioplasty (Fig. 2) was performed resulting in blood

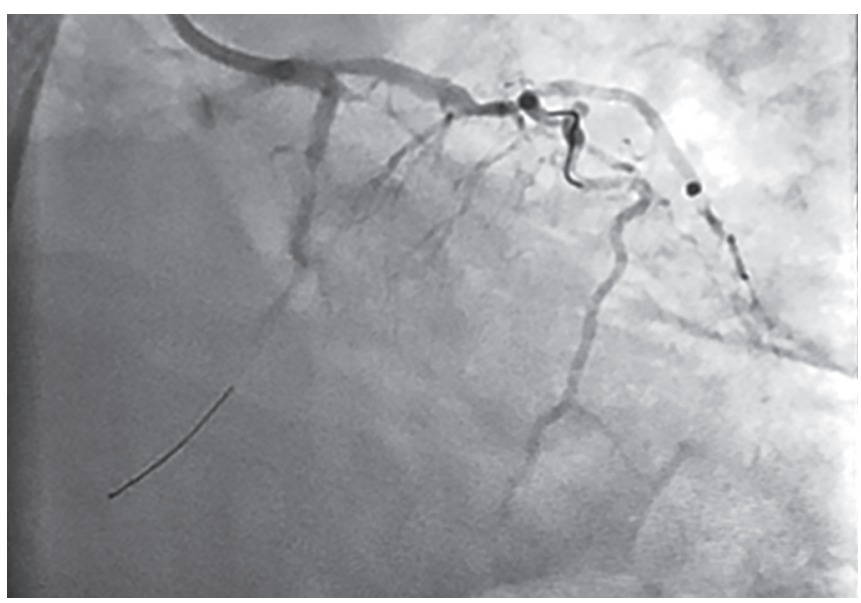

Fig. 1: Angioplasty guidewire in circumflex artery without visualization of obtuse marginal branches

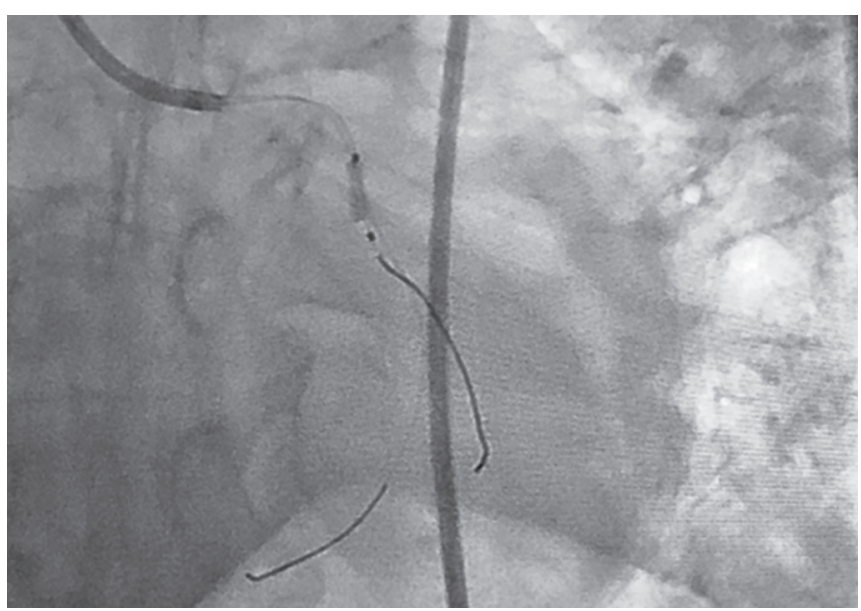

Fig. 2: Angioplasty 


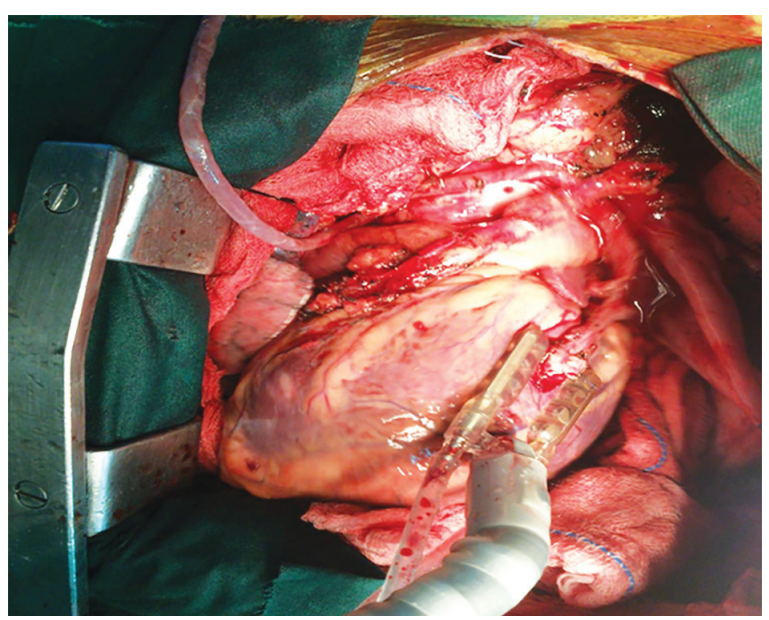

Fig. 3: Left internal mammary artery to $L A D$ and vein graft to diagonal branch on beating heart

flow to the distal part of circumflex artery. A residual stenosis persisted in the circumflex artery which was unyielding to angioplasty, and stent could not be placed.

As a result of partial revascularization, hemodynamics improved with cardiac index increasing to $2 \mathrm{~L} / \mathrm{min} / \mathrm{m}^{2}$. The ST segment elevations on electrocardiogram decreased in magnitude but still persisted. Pulmonary congestion was treated aggressively with diuretics, and prophylactic antibiotics were administered.

Patient also had episodes of ventricular arrhythmias. In view of persisting ischemia and cardiogenic shock, it was decided to complete the vascularization with coronary bypass grafting, and patient was taken up for CABG.

\section{Surgical Procedure}

Median sternotomy was done and left ventricle was found to be severely hypokinetic. Heparin was administered. Left internal mammary artery was harvested and anastomosed to left anterior descending artery (LAD; Fig. 3). Three vein conduits were harvested and were anastomosed to aorta proximally. On beating heart, one vein graft was anastomosed to distal right coronary artery. One vein graft was anastomosed to diagonal branch. In view of severe hypokinesia of left ventricle and tendency to develop arrhythmias, it was decided to do the rest of revascularization on decompressed heart, so cardio pulmonary bypass was established with aortic and two-stage venous cannulation. Vein graft was anastomosed sequentially into two obtuse marginal branches. Postgrafting, heart was rested on CPB for 20 minutes. Heart was slowly weaned off $\mathrm{CPB}$ with moderate inotropic support. Cardiac contractility was visibly better and cardiac index improved to $3 \mathrm{~L} / \mathrm{min} / \mathrm{m}^{2}$. ST elevations subsided.

\section{Postoperative Course}

Postoperative bleeding was minimal and one unit of blood was transfused to maintain a hematocrit of 27 .
Hemodynamics was maintained with optimal systemic vascular resistance and pulmonary vascular resistance as indicated by cardiac output deductions. Arrhythmias were treated with amiodarone, and it disappeared on day 2.

Patient was electively ventilated for 36 hours till steady hemodynamics was achieved with no arrhythmias and good arterial blood gases. Patient was weaned off ventilator and extubated on day 2. The IABP was removed on day 4 . Inotropes were gradually reduced, and patient was given chest physiotherapy, active and passive physiotherapy to limbs other than the fractured one.

Patient was transferred to orthopedic department side on day 12. Patient subsequently underwent hip replacement after 3 months.

\section{DISCUSSION}

Cardiogenic shock post-MI with ongoing ischemia is a difficult problem to manage. Primary angioplasty is carried out in possible situations with culprit vessel stenting. Situation becomes very precarious when angioplasty is insufficient and does not relieve the coronary stenosis. If left untreated, re-infraction is the result with grave consequences including mortality.

In such situations, a hybrid procedure comprising angioplasty and CABG can give remarkable results. ${ }^{1}$

In our case, patient had severe LVF and pulmonary edema. The IABP, ventilation, antifailure measures, and antiarrhythmic measures bought some time to do angiogram and rescue angioplasty of circumflex artery, which was deemed to be the culprit vessel. Although stenosis persisted, partial revascularization improved myocardial perfusion in a severely ischemic heart which stabilized the hemodynamics significantly but not completely.

Coronary artery bypass grafting in the setting of cardiogenic shock post-MI carries higher morbidity and mortality than elective cases, but may become inevitable in the presence of ongoing ischemia. If the hemodynamics is stabilized as much as possible and organ perfusion is maintained by various measures, CABG can bail out such critical patients. ${ }^{1}$ Precautions to counter sepsis also has a significant role in the process.

In our case, part of coronary grafting was done on beating heart under stable conditions without much displacement of heart. Obtuse marginal vessel grafting which required considerable displacement of the heart was done on CPB with the heart decompressed. This whole procedure had following advantages:

- Total CPB time was kept to minimum to reduce the deleterious effects of $\mathrm{CPB}$, such as pulmonary/kidney dysfunction, sepsis, and platelet dysfunction.

- Heart was put to minimal stress while revascularization was done. 
- Decompressed heart allowed it to recover from the stress of MI, which was helped by simultaneous revascularization.

- Catastrophic events like arrhythmias/cardiac arrest, which would damage the already jeopardized heart and other organs, were totally avoided resulting in optimal organ preservation.

- Short bypass time resulted in minimal bleeding and transfusions which directly led to stable postoperation conditions and faster recovery.

\section{CONCLUSION}

Thus, hybrid procedure of combining angioplasty and CABG can salvage difficult situation of post-MI cardiogenic shock with ongoing ischemia. Immediate coronary angiography with primary angioplasty and CABG, when appropriate in patients with AMI, can be performed safely and effectively with good outcome. In conclusion, hybrid revascularization is a safe and effective method for high-risk patients. ${ }^{1}$

\section{REFERENCES}

1. Us MH, Basaran M, Yilmaz M, Yaymaci B, Ulusoy E, Sanioglu S, Ozbek C, Arslan Y, Pocan S, Yilmaz AT. Hybrid coronary revascularization in high-risk patients. Tex Heart Inst J 2006;33(4): 458-462.

2. Chamberlain MH, Ascione R, Reeves BC, Angelini GD. Evaluation of the effectiveness of off-pump coronary artery bypass grafting in high-risk patients: an observational study. Ann Thorac Surg 2002 Jun;73(6):1866-1873.

3. Riess FC, Bader R, Kremer P, Kuhn C, Kormann J, Mathey D, Moshar S, Tuebler T, Bleese N, Schofer J. Coronary hybrid revascularization from January 1997 to January 2001: a clinical follow-up. Ann Thorac Surg 2002 Jun;73(6):1849-1855.

4. Stamou SC, Jablonski KA, Hill PC, Bafi AS, Boyce SW, Corso PJ. Coronary revascularization without cardiopulmonary bypass versus the conventional approach in high-risk patients. Ann Thorac Surg 2005 Feb;79(2):552-557.

5. Cisowski M, Morawski W, Drzewiecki J, Kruczak W, Toczek K, Bis J, Bochenek A. Integrated minimally invasive direct coronary artery bypass grafting and angioplasty for coronary artery revascularization. Eur J Cardiothorac Surg 2002 Aug;22(2):261-265. 